\title{
The linguistic and cognitive profile of Down syndrome: Evidence from a comparison with fragile $X$ syndrome
}

\author{
Leonard Abbeduto', Melissa Pavetto', Erica Kesin², Michelle D. Weissman³, \\ Selma Karadottir', Anne O'Brien', and Stephanie Cawthon'
}

\author{
'Waisman Center, University of Wisconsin-Madison, Madison, Wisconsin, U.S.A. \\ ${ }^{2}$ Department of Curriculum and Instruction, University of Wisconsin-Madison, U.S.A. \\ ${ }^{3}$ California State at Sacramento, U.S.A.
}

\begin{abstract}
In this paper, we report on the results of our research, which is designed to address two broad questions about the cognitive and linguistic profile of Down syndrome: (I) Which domains of functioning are especially impaired in individuals with Down syndrome? and (2) Which aspects of the language and cognitive profile of Down syndrome are syndrome specific? To address these questions, we focused on three dimensions of the Down syndrome profile - receptive language, expressive language, and theory of mind - and made comparisons to individuals with fragile $X$ syndrome, which is an X-linked form of intellectual disability. We identified Down syndrome impairments on all three dimensions that were substantially greater than those seen in nonverbal cognition and that were not shared by individuals with fragile $X$ syndrome. Clinical implications of these findings are considered.
\end{abstract}

Keywords - Down syndrome, fragile $X$ syndrome, receptive language, expressive language, theory of mind, syndrome specificity

\section{Introduction}

We are currently engaged in research designed to address two broad questions about the linguistic and cognitive profile of Down syndrome. The first question is: Which domains of functioning are especially impaired in individuals with Down syndrome? This is the domain asynchrony question. It is an important question for both pedagogical and theoretical reasons. From a pedagogical perspective, answers to this question will allow us to design more effective education and therapy (Hodapp, 1998). For example, we might decide to give more intensive therapy in areas of greatest weakness or design a curriculum for school that circumvents certain weaknesses, thereby maximizing acquisition of educational content. From a theoretical perspective, answers to the domain asynchrony question provide insights into dependencies among domains, thereby illuminating the mechanisms of development - typical as well as atypical (Abbeduto, Evans \& Dolan, 2001). In language research, for example, data on domain asynchronies have informed discussions about modularity and innateness (e.g., Rondal, 1995). In fact, many researchers interested in Down syndrome have devoted considerable attention and resources to the domain asynchrony question (see Chapman \& Hesketh, 2000, for a comprehensive review).

The second question addressed in our research is: Which aspects of the linguistic and cognitive profile of Down syndrome are syndrome specific? In other words, which features are more likely to characterize individuals with Down syndrome than individuals with other genetic conditions associated with intellectual disabilities? This is the syndrome specificity question (Dykens, Hodapp \& Finucane, 2000). Again, this question is important for both theoretical and pedagogical reasons. From a theoretical perspective, identification of syndrome-specific properties of the behavioural phenotype of any syndrome is essential if we are ever to understand the role of the genes underlying the syndrome (Hodapp \& Dykens, 1994). From a pedagogical perspective, knowing which problems are syndrome specific and which common to all syndromes associated with intellectual abilities provides a sort of "advance organizer" for those planning assessments or therapies for individual clients (Hodapp \& Fidler, 1999). Unfortunately, few data are available to address the syndrome specificity question. 
Answering the syndrome specificity question requires comparison of the performance of individuals with Down syndrome in the domain of interest to that of individuals affected by some other syndrome. Such comparisons, however, have until recently been surprisingly rare (Hodapp \& Dykens, 1994). Moreover, many of the comparisons that have been made have not always been motivated by an interest in Down syndrome per se, but rather by an interest in some other condition. An example is provided by research on an aspect of social cognition in individuals with autism referred to as theory of mind. Researchers interested in autism have used Down syndrome as the "prototypical" case of intellectual disability. By comparing the theory of mind performance of individuals with autism to that of individuals with Down syndrome, they have been able to identify deficits that are specific to autism rather than being shared by other conditions associated with intellectual disabilities (Yirmiya, Erel, Shaked \& Solomica-Levi, 1998). Because the focus of such studies has been on autism rather than on Down syndrome, however, the participants have not always been selected or matched in a way that illuminates the theory of mind problems of individuals with Down syndrome.

In our research, we have jointly addressed the domain asynchrony and syndrome specificity questions by comparing the cognitive and linguistic performance of individuals with Down syndrome to that of individuals with fragile $\mathrm{X}$ syndrome. Fragile X syndrome is an X-linked genetic disorder (Batshaw, 1997). With a prevalence of 1 in 4, 000 for males and 1 in 8, 000 for females (Hagerman, 1999), fragile $\mathrm{X}$ syndrome is second only to Down syndrome as a genetic cause of intellectual disabilities (Dykens et al., 2000 ). Fragile $X$ syndrome results from a change in a single gene on the $\mathrm{X}$ chromosome - the FMRl gene (Hagerman, 1999). The change involves an excessive lengthening of a repetitive sequence of the trinucleotides that comprise the DNA molecule (the CGG repeats). The excessive lengthening typically leads to a chemical change called methylation, which turns off the gene, preventing the gene from producing its protein, FMRP (Hagerman, 1999). FMRP is normally expressed in many tissues throughout the body, with especially high concentrations in the central nervous system (Hagerman, 1999). Because fragile X syndrome is $\mathrm{X}$-linked, males are more affected than are females (Batshaw, 1997). Fully affected males typically have IQs between 40 and 60 , whereas fully affected females have either a mild intellectual disability or learning problems in a more circumscribed domain, such as mathematics (Dykens et al., 2000).

Fragile X syndrome provides a useful comparison for Down syndrome for at least three reasons. First, the IQ level achieved in fragile $\mathrm{X}$ syndrome, particularly by males with the full mutation, is typically similar to that observed in individuals with DS. This similarity in IQ range is important because it allows us to interpret group differences between Down syndrome and fragile X syndrome as being related to syndrome rather than to IQ. Second, there are some interesting differences between the syndromes despite the similarity in IQ range. In particular, the incidence of maladaptive behaviours and various psychopathologies (e.g., hyperactivity, attentional problems, social anxiety, and autistic-like behaviours) is greater in fragile $\mathrm{X}$ syndrome than in Down syndrome. Consequently, the comparison of Down syndrome and fragile $\mathrm{X}$ syndrome can yield insights into the impact of maladaptive behaviour and psychopathology on language and cognition. Third, the comparison of Down syndrome and fragile X syndrome can yield educationally and theoretically valuable information about both of these relatively frequently occurring syndromes.

In the remainder of this paper, we present preliminary data from our research on three dimensions of the linguistic and cognitive profile of individuals with Down syndrome and individuals with fragile $\mathrm{X}$ syndrome: (1) receptive language; (2) expressive language; and (3) theory of mind. The participants in this research consisted of three groups. The first group was comprised of 25 individuals who had Down syndrome due to trisomy 21 . These individuals ranged in age from 11.5 years to 23 years. We administered three nonverbal subtests from the Stanford-Binet Intelligence Scale, $4^{\text {th }}$ edition (Thorndike, Hagen \& Sattler, 1986) - Bead Memory, Pattern Analysis, and Copying - so that we could determine a developmental level, or mental age, that reflected cognitive ability but not language ability. The mental ages of the participants with Down syndrome ranged from approximately three to seven, with an average near four years. The second group of participants consisted of 18 individuals with fragile $\mathrm{X}$ syndrome who were matched groupwise to the participants with Down syndrome in terms of chronological age, nonverbal mental age, and nonverbal IQ. The group with fragile X syndrome was predominantly male, but included some females as well. ${ }^{1}$ The third group of participants consisted of 24 typically developing 3- to 6-year-olds who were matched to the other two groups of participants in terms of nonverbal mental age (MA).

\section{Receptive Language}

Previous research has demonstrated that many individuals with Down syndrome have impairments in at least some domains of receptive language that exceed their impairments in the cognitive domain (e.g., Chapman, Schwartz \& Kay-Raining Bird, 1991). What is less clear from this research, however, is whether the asynchrony noted between receptive language and cognitive development is unique to Down syndrome or extends to other aetiological groups as well. In other words, we have no answer to the syndrome specificity question. In our project, we sought to replicate the previously documented finding of a receptive language-

${ }^{1}$ Males with fragile X syndrome outperformed females with fragile $\mathrm{X}$ syndrome on all measures we have examined to date, as expected. However, we have not observed any qualitative differences between males and females with fragile $\mathrm{X}$ syndrome as regards, for example, the extent to which there are or are not asynchronies across the various domains of interest. 
cognition asynchrony and determine whether it extended to fragile $\mathrm{X}$ syndrome. This led us to ask the following two questions: (1) Are the receptive language problems of individuals with Down syndrome more severe than their problems in nonverbal cognition? and (2) Are the receptive language problems of individuals with Down syndrome more severe than those of individuals with fragile $X$ syndrome?

Our measure of receptive language was the Test for Auditory Comprehension of Language-Revised, or TACL-R (Carrow-Woolfolk, 1985). This is a popular standardized test in which the participant selects the one drawing from a set of three that matches the meaning of each target item spoken by the examiner. The TACL- $\mathrm{R}$ is organized into three subtests: Word Classes and Relations, which is focused largely on vocabulary; Grammatical Morphemes, which is focused on prepositions and bound morphemes, such as the past tense and plural; and Elaborated Sentences, which is focused on various multiword syntactic patterns, such as the passive, the interrogative, and the relative clause. The TACL-R yields age-equivalent scores and standard scores for the test as a whole, as well as for the various subtests. Age-equivalent scores indicate the age at which children typically achieve such a score, whereas standard scores provide information about how the examinee's score compares to his or her chronological age peers.

\section{Are the receptive language problems of individuals with Down syndrome more severe than their problems in nonverbal cognition?}

A comparison of the TACL-R scores of the group with Down syndrome and the typically developing group provided a "yes" answer to this question. We found that, as a group, the participants with Down syndrome had lower age-equivalent scores on the TACL-R than did the mental age-matched typically developing children. This demonstrates that the ability of individuals with Down syndrome to understand spoken language is more impaired than are their nonverbal cognitive skills, as measured with the Stanford-Binet subtests.

\section{Are the receptive language problems of individuals with Down syndrome more severe than those of individuals with fragile $X$ syndrome?}

A comparison of the TACL-R scores of the participants with Down syndrome and the participants with fragile $\mathrm{X}$ syndrome provided a "yes" answer to this question. The group with Down syndrome did more poorly in terms of both their age-equivalent scores and standard scores than did the group with fragile $\mathrm{X}$ syndrome. In contrast, the group with fragile $\mathrm{X}$ syndrome did not differ in their ageequivalent scores from the typically developing groups. This demonstrates that the asynchrony between receptive language and nonverbal cognition that is characteristic of Down syndrome is not shared by fragile $\mathrm{X}$ syndrome. These findings are consistent with the hypothesis that the asynchrony is specific to Down syndrome.

In addition to examining the total, or whole test, scores for the TACL- $\mathrm{R}$, we also examined scores on the various subtests. The results of these analyses provide us even more detailed answers to our domain asynchrony and syndrome specificity questions. We found that the participants with Down syndrome did more poorly on the two grammar-oriented subtests (i.e., Grammatical Morphemes and Elaborated Sentences) than on the semantically-oriented subtest (i.e., Word Classes and Relations). No such asynchrony was seen for the other two groups of participants. These findings suggest that not all facets of receptive language are equally problematic for individuals with Down syndrome, and that what is unique to Down syndrome is an asynchrony between receptive grammar and nonverbal cognitive ability.

\section{Expressive Language}

Previous research has demonstrated that the vast majority of individuals with Down syndrome have great difficulty in the domain of expressive language (see Chapman \& Hesketh, 2000, for a review). There is evidence that impairments in expressive language emerge early in development, as demonstrated by a substantially delayed onset of the transition from babble to meaningful speech (Lynch \& Eilers, 1991); increase in severity during childhood (Fowler, Gleitman \& Gleitman, 1994); and exceed in severity not only the impairments in nonverbal cognition typically associated with Down syndrome, but the impairments in receptive language as well (Chapman, Seung, Schwartz \& Kay-Raining Bird, 1998).

Despite the considerable evidence gathered to document the asynchrony between expressive language and other aspects of development, however, it is not clear from previous research whether the asynchrony is unique to Down syndrome or extends to other aetiological groups. In other words, here too we have no answer to the syndrome specificity question. There is evidence that the asynchrony is not shared by most individuals with Williams syndrome (Bellugi, Lai \& Wang, 1997). It is not clear, however, whether the asynchrony is shared by individuals with other genetic conditions, including fragile $\mathrm{X}$ syndrome. There have been several studies in which the expressive language performance of individuals with Down syndrome was compared to that of individuals with fragile $\mathrm{X}$ syndrome (e.g., Ferrier, Bashir, Meryash, Johnston \& Wolff, 1991; Sudhalter, Cohen, Silverman \& Wolf-Schein, 1990). These comparisons of Down syndrome and fragile $\mathrm{X}$ syndrome, however, largely focused on only very narrowly defined dimensions of expressive language performance (e.g., perseveration) or did not involve appropriately matched groups (e.g., groups matched on highly verbal measures of cognitive ability; Abbeduto \& Hagerman, 1997). We, therefore, sought to replicate the finding of a Down syndrome asynchrony between expressive language and other domains and test its generalisability to fragile $\mathrm{X}$ syndrome. This led us to ask the following two questions: (1) Are the expressive language problems of individuals with Down syndrome more severe than their problems in nonverbal cognition and receptive language? and (2) Are the expressive language problems of individuals with Down syndrome more severe than those of individuals with fragile $X$ syndrome? 
In our project, we are administering numerous measures of expressive language ability to our research participants; however, we have fully analysed data from only one measure: the Oral Expression subtest from the Oral and Written Language Scales, or OWLS (Carrow-Woolfolk, 1995). This is a recently developed standardized test in which the participant is asked to respond to verbal prompts from the examiner in order to describe various pictured events. Target responses range from a single word to a complete sentence and even a brief paragraph at the upper end of the subtest. The target responses are themselves designed to assess a range of semantic, syntactic, and pragmatic skills. Raw scores are convertible into both standard scores and age-equivalent scores. In contrast to the TACL-R, however, scores on the OWLS are calculable only for the whole test - separate domain scores are not possible.

\section{Are the expressive language problems of individuals with Down syndrome more severe than their problems in nonverbal cognition and receptive language?}

A comparison of the OWLS scores of the group with Down syndrome and the typically developing group provided a "yes" answer to this question. We found that, as a group, the participants with Down syndrome had lower age-equivalent scores on the OWLS than did the MA-matched typically developing children. This demonstrates that the ability of individuals with Down syndrome to express themselves through spoken language is more impaired than are the nonverbal cognitive skills that we measured with the Stanford-Binet subtests. Moreover, we found that the OWLS age-equivalent scores of the participants with Down syndrome were substantially lower than their TACL-R ageequivalents - a difference that was not seen for the typically developing participants. This latter finding suggests that the expressive problems of individuals with Down syndrome are more severe than their problems in the receptive domain.

\section{Are the expressive language problems of individuals with Down syndrome more severe than those of individuals with fragile $X$ syndrome?}

A comparison of the OWLS scores of the participants with Down syndrome and the participants with fragile $\mathrm{X}$ syndrome provided a "yes" answer to this question. The group with Down syndrome did more poorly in terms of both their age-equivalent and standard scores than did the group with fragile $\mathrm{X}$ syndrome. In contrast, the group with fragile $\mathrm{X}$ syndrome did not differ in their age-equivalent scores from the typically developing group. We also found that, like the typically developing participants, the group with fragile X syndrome displayed no difference in their performance on the OWLS and TACL-R. These results replicate the finding of an especially severe problem in expressive language for individuals with Down syndrome and demonstrate that this asynchrony is not characteristic of fragile $\mathrm{X}$ syndrome. Again, this is consistent with the hypothesis that the asynchrony is specific to Down syndrome.

Before leaving the topic of expressive language, it is important to note that preliminary results from our other measures of expressive language support and extend the foregoing conclusions. In particular, we have begun to analyse samples of conversation and narration obtained from our participants. We analysed the samples from a subset of our participants with Down syndrome and with fragile $\mathrm{X}$ syndrome and calculated scores for lexical diversity, talkativeness, fluency, intelligibility, and syntactic complexity. We found that the participants with Down syndrome obtained scores reflecting less advanced language ability; however, this difference emerged only for syntactic complexity. This finding should be interpreted with considerable caution given the limited number of samples analysed. Nevertheless, the results are consistent with those from the OWLS in suggesting a Down syndrome asynchrony between expressive language, on the one hand, and nonverbal cognition and receptive language, on the other. The results are also consistent with those of the TACL-R in suggesting that underlying the asynchrony is a deficit in grammar.

\section{Theory of Mind}

Theory of mind refers to the coherent body of knowledge about the human mind that we typically use to predict and explain our own behaviour and that of others (Astington, 1994). Theory of mind is a dimension of social cognition, and it is the foundation for performance in a number of important social tasks, including meeting the informational needs of one's listener (Frith, 1996), creating a coherent and comprehensible narrative (Astington, 1994), soliciting confirmation of one's interpretation of another person's sentences (Abbeduto, Short-Meyerson, Benson, Dolish \& Weissman, 1998), reacting to emotional distress in others (Tager-Flusberg \& Sullivan, 1994a), and even deception (Sodian \& Frith, 1992). Previous research with aetiologically heterogeneous groups of persons with intellectual disabilities has shown theory of mind to be substantially delayed (Tager-Flusberg \& Sullivan, 1994b), perhaps even to the point of lagging behind nonverbal MA in some individuals (Benson, Abbeduto, Short, Nuccio \& Maas, 1993). Previous research has also shown there to be genetic syndrome-related differences in theory of mind, with some evidence of a relative sparing of theory of mind skills in individuals with Williams syndrome (Karmiloff-Smith, Klima, Bellugi, Grant \& Baron-Cohen, 1994). Down syndrome, however, has been studied less frequently with respect to theory of mind, at least in a manner that addresses both the domain asynchrony and syndrome specificity questions. In our research, therefore, we have addressed the following two questions: (1) Are the theory of mind problems of individuals with Down syndrome more severe than their problems in nonverbal cognition? and (2) Are the theory of mind problems of individuals with Down syndrome more severe than those of individuals with fragile $X$ syndrome?

To measure theory of mind in our three groups of participants, we used what has been called a false belief task (Benson et al., 1993). The aim of such tasks is to assess the ability of the participant to reason about another person's beliefs when those beliefs are different from his or 
her own. The ability to deal effectively with false beliefs is seen by many theorists (Perner, 1988) to be the foundation of a mature theory of mind. Although there are many false belief tasks in use today, they all share a common structure. In particular, the participant witnesses a narrated story enacted with props or illustrated with drawings. The critical feature of the story is that a character believes something that the participant knows to be false. After hearing the story, the participant is asked test questions designed to determine whether he or she recognises that: (1) the character holds a false belief and (2) the character's behaviour will be governed by that belief. Variations in the difficulty of the reasoning required can be introduced, the most popular of which involves the distinction between first-order and second-order reasoning (Tager-Flusberg \& Sullivan, 1994b). First-order reasoning involves evaluating another persons' representation of some state of affairs in the world (e.g. Does John know X?); second-order reasoning involves evaluation of another person's representation of yet another person's representation of some state of affairs in the world (e.g. Does John know that Mary knows X?).

The false belief task we used to assess first- and secondorder reasoning was based on work by Tager-Flusberg and Sullivan (1994b). We created false beliefs in our story characters by changing the location of an object and by controlling which characters saw the change occur or saw another character find out about the change. In addition to asking test questions, we also asked a variety of control questions, which were designed to evaluate whether the participant (1) was able to track the object's change of location, (2) understood which characters had and had not witnessed or learned of the change, and (3) was capable of processing the linguistic structure of the test questions. By asking control questions, we were able to determine whether a participant's failure on the test questions reflected theory of mind problems or problems understanding the language or events used in the task.

\section{Are the theory of mind problems of individuals with Down syndrome more severe than their problems in nonverbal cognition?}

An analysis of the proportion of correct responses on the test questions provided a "yes" answer to this question. We found that the participants with Down syndrome, as a group, answered substantially fewer test questions correctly than did the typically developing participants. This finding demonstrates that the ability of individuals with Down syndrome to reason about the mental states of a person who holds beliefs different from their own is more impaired than are their nonverbal cognitive skills, as measured by the Stanford-Binet subtests.

\section{Are the theory of mind problems of individuals with Down syndrome more severe than those of individuals with fragile $X$ syndrome?}

A comparison of the participants with Down syndrome to the participants with fragile $\mathrm{X}$ syndrome in terms of the proportion of correct responses on the test questions yielded a "yes" answer to this question. We found that the group with Down syndrome was less apt to answer correctly than was the group with fragile $\mathrm{X}$ syndrome. In fact, the group with fragile $\mathrm{X}$ syndrome performed as well on the test questions as did the typically developing participants. These findings demonstrate that the asynchrony between theory of mind and nonverbal cognition that we observed for Down syndrome is not shared by fragile X syndrome, which is consistent with the hypothesis that this asynchrony may be a unique feature of the Down syndrome behavioural phenotype.

It is important to note that there was evidence that the problems that the participants with Down syndrome had with the test questions truly reflected theory of mind problems rather than language problems. The group with fragile $\mathrm{X}$ syndrome answered no more control questions correctly than did the group with Down syndrome, yet the group with fragile X syndrome did substantially better on the test questions than did the group with Down syndrome. In addition, when we limited our analyses to only those participants who answered all the control questions correctly, we still found that the participants with Down syndrome were less likely to answer the test questions correctly than were the participants in either the fragile X syndrome group or the typically developing group. Thus, it appears that there is something about theory of mind that is problematic for individuals with Down syndrome and that this involves more than an inability to process language.

\section{Conclusion}

We have addressed questions about the domain asynchrony and syndrome specificity of the cognitive and linguistic problems that affect individuals with Down syndrome. By doing so, we have identified three dimensions of cognitive and linguistic functioning - receptive grammar, expressive grammar, and theory of mind - that are important for understanding the behavioural phenotype of Down syndrome. These dimensions are especially impaired in Down syndrome and may discriminate Down syndrome from other syndromes associated with intellectual disabilities. This information should lead to assessment and intervention plans that are better tailored to the problems likely to be facing an individual with Down syndrome who needs services in school or the workplace.

Despite progress in addressing the domain asynchrony and syndrome specificity questions, there is much that remains to be learned. As regards domain asynchrony, it is not yet clear how the impairments in receptive grammar, expressive grammar, and theory of mind that we have described combine to shape performance in more complex everyday behaviours, such as speaking and listening in real social situations at home, at school, and in the community. Indeed, there is some evidence, albeit limited, that individuals with Down syndrome have more sophisticated communication skills than would be predicted from the severity of their deficits in language or theory of mind (Dykens et al., 2000). How is this possible? What strategies or experiences are available to the individual with Down syndrome 
that allows him or her to circumvent, in part, the very real deficits in receptive grammar, expressive grammar, and theory of mind? Identification of these strategies and experiences may hold the key to the development of optimal educational interventions and therapies. Although we have yet to identify these strategies and experiences, it may be that the low rate of psychopathologies and maladaptive behaviours in individuals with Down syndrome (relative to, for example, individuals with fragile $\mathrm{X}$ syndrome) and their tendency to prefer social interaction over object-oriented activities (Dykens et al., 2000) may be involved.

As regards syndrome specificity, it is important to note that our data are limited because they reflect comparisons with only one other syndrome - fragile X syndrome. Although our results suggest that fragile $\mathrm{X}$ syndrome provides a useful comparison for Down syndrome, we must include many other diagnostic groups before we can be confident that the deficits we have described for Down syndrome are truly syndrome specific.

\section{Correspondence}

Leonard Abbeduto - Waisman Center, University of Wisconsin-Madison, 1500 Highland Avenue, Madison, Wisconsin 53705, USA • E-mail:

abbeduto@waisman.wisc.edu

\section{Acknowledgment}

The research described in this paper was supported by grants R01 HD24356 and P30 HD03352 from the National Institutes of Health. The authors acknowledge the assistance of Shannon Theis Romanski and Elizabeth Wall in transcribing the language samples. We are indebted to the many families who participated in the project. Without their support and patience, this research would not have been possible. Thanks also to Marcia Braden, Ph.D., and Vicki Sudhalter, Ph.D., for their advice and support during the early stages of the project and to Susan Vial for help recruiting families.

\section{References}

Abbeduto, L., Evans, J., \& Dolan, T. (2001) Progress in understanding language and communication problems in mental retardation and developmental disabilities. Mental Retardation and Developmental Disabilities Research Reviews, 1, 45-55.

Abbeduto, L., \& Hagerman, R. (1997). Language and communication in fragile X syndrome. Mental Retardation and Developmental Disabilities Research Reviews, 3, 313-322.

Abbeduto, L., Short-Meyerson, K., Benson, G., Dolish, J., \& Weissman, M. (1998). Understanding referential expressions: Use of common ground by children and adolescents with mental retardation. Journal of Speech, Language, and Hearing Research, 41, 348-362.

Astington, J. W. (1994). Children's developing notions of others' minds. In J. F. Duchan, L. E. Hewitt, \& R. M. Sonnenmeier (Eds.), Pragmatics: From Theory to Practice. (pp. 72-87). Englewood Cliffs, NJ: Prentice Hall.
Batshaw, M. L. (1997). Fragile X syndrome. In M. L. Batshaw (Ed.), Children with Disabilities, $4^{\text {th }}$ edition (pp. 377-388). Baltimore: Brookes.

Bellugi, U., Lai, Z. \& Wang, P. (1997). Language, communication, and neural systems in Williams syndrome. Mental Retardation and Developmental Disabilities Research Reviews, 3, 334-342.

Benson, G., Abbeduto, L., Short, K., Nuccio, J. B., \& Maas, F. (1993). Development of a theory of mind in persons with mental retardation. American Journal on Mental Retardation, 98, 427-433.

Carrow-Woolfolk, E. (1985). Test for Auditory Comprehension of Language-Revised. Allen, TX: DLM Teaching Resources.

Carrow-Woolfolk, E. (1995). Oral and Written Language Scales. Circle Pines, MN: American Guidance Services.

Chapman, R. S., \& Hesketh, L. J. (2000). The behavioral phenotype of individuals with Down syndrome. Mental Retardation and Developmental Disabilities Research Reviews, 6, 84-95.

Chapman, R. S., Schwartz, S.E. \& Kay-Raining Bird, E. (1991). Language skills of children and adolescents with Down syndrome I. Comprehension. Journal of Speech and Hearing Research, 34, 1106-1120.

Chapman, R.S., Seung, H. K., Schwartz, S. E. \& Kay-Raining Bird, E. (1998). Language skills of children and adolescents with Down syndrome II. Production deficits. Journal of Speech and Hearing Research, 41, 861-873.

Dykens, E. M., Hodapp, R. M. \& Finucane, B. M. (2000). Genetics and Mental Retardation Syndromes: A New Look at Behavior and Interventions. Baltimore: Brookes.

Ferrier, L. J., Bashir, A.S., Meryash, D.L., Johnston, J., \& Wolff, P. (1991). Conversational skills of individuals with fragile $\mathrm{X}$ syndrome: A comparison with autism and Down syndrome. Developmental Medicine and Child Neurology, 33, 776-788.

Fowler, A. E., Gelman, R., \& Gleitman, L. R. (1994). The course of language learning in children with Down syndrome: Longitudinal and language level comparisons with young normally developing children. In H. TagerFlusberg (Ed.), Constraints on Language Acquisition: Studies of Atypical Children (pp. 91-140). Hillsdale, NJ: Lawrence Erlbaum Associates.

Frith, U. (1996). Social communication and its disorder in autism and Asperger syndrome. Journal of Psychopharmacology, 10, 48-53.

Hagerman, R. J. (1999). Neurodevelopmental Disorders. Oxford: Oxford University Press.

Hodapp, R. M. (1998). Development and Disabilities: Intellectual, Sensory, and Motor Impairments. Cambridge: Cambridge University Press.

Hodapp, R. M., \& Dykens, E. M. (1994). Mental retardation's two cultures of behavioral research. American Journal on Mental Retardation, 98, 675-687.

Hodapp, R. M., \& Fidler, D. J. (1999). Special education and genetics: Connections for the $21^{\text {st }}$ century. The Journal of Special Education, 33, 130-137.

Karmiloff-Smith, A., Klima, E., Bellugi, U., Grant, J., \& Baron-Cohen, S. (1994). Is there a social module? Language, face processing, and theory of mind in individuals 
with Williams syndrome. Journal of Cognitive Neuroscience, 10, 197-208.

Lynch, M. P., \& Eilers, R. E. (1991). Perspectives on early language from typical development and Down syndrome. In N. W. Bray (Ed.). International Review of Research in Mental Retardation (pp. 55-90). New York: Academic Press.

Perner, J. (1988). Higher-order beliefs and intentions in children's understanding of social interaction. In J. W. Astington, P. L. Harris, \& D. R. Olson (Eds.), Developing Theories of Mind (pp. 271-294). New York: Cambridge University Press.

Rondal, J. A. (1995). Exceptional Language Development in Down Syndrome: Implications for the Cognition-Language Relationship. Cambridge: Cambridge University Press.

Sodian, B., \& Frith, U. (1992). Deception and sabotage in autistic, retarded, and normal children. Journal of Child Psychology and Psychiatry, 33, 591-605.

Sudhalter, V., Cohen, I. L., Silverman, W., \& Wolf-Schein, E.G. (1990). Conversational analyses of males with frag- ile X, Down syndrome, and autism: Comparison of the emergence of deviant language. American Journal on Mental Retardation, 94, 431-441.

Tager-Flusberg, H., \& Sullivan, K. (1994a). Predicting and explaining behavior: A comparison of autistic, mentally retarded and normal children. Journal of Child Psychology and Psychiatry, 35, 1059-1075.

Tager-Flusberg, H., \& Sullivan, K. (1994b). A second look at second-order belief attribution in autism. Journal of Autism and Developmental Disorders, 24, 577-586.

Thorndike, R. L., Hagen, E. P., \& Sattler, J. M. (1986). Stanford-Binet Intelligence Scale: Fourth edition. Chicago: Riverside Publishing.

Yirmiya, N., Erel, O., Shaked, M., \& Solomonica-Levi, D. (1998). Meta-analyses comparing theory of mind abilities of individuals with autism, individuals with mental retardation, and normally developing individuals. Psychological Bulletin, 124, 283-307. 